\title{
Tinzaparin inhibits VL30 retrotransposition induced by oxidative stress and/or VEGF in HC11 mouse progenitor mammary cells: Association between inhibition of cancer stem cell proliferation and mammosphere disaggregation
}

\author{
STEFANIA MANTZIOU ${ }^{1}$, GEORGIOS MARKOPOULOS ${ }^{1,2}$, \\ SOTEROULA THRASYVOULOU ${ }^{1}$, DIMITRIOS NOUTSOPOULOS ${ }^{1}$, FOTEINI GKARTZIOU $^{1}$, \\ GEORGIOS VARTHOLOMATOS ${ }^{3}$ and THEODORE TZAVARAS ${ }^{1}$
}

\author{
${ }^{1}$ Laboratory of General Biology, Faculty of Medicine, School of Health Sciences, University of Ioannina; \\ ${ }^{2}$ Biomedical Research Division, Institute of Molecular Biology and Biotechnology, Foundation for Research and Technology; \\ ${ }^{3}$ Molecular Biology Unit, Hematology Laboratory, University Hospital of Ioannina, 45110 Ioannina, Greece
}

Received April 21, 2021; Accepted July 15, 2021

DOI: $10.3892 /$ or.2021.8192

\begin{abstract}
Tinzaparin is an anticoagulant and antiangiogenic drug with inhibitory properties against tumor growth. VEGF stimulates angiogenesis, while an association between reactive oxygen species (ROS) and angiogenesis is involved in tumor progression. The present study aimed to investigate the effect of tinzaparin on VL30 retrotransposition-positive mouse HC11 mammary stem-like epithelial cells, previously reported to be associated with induced mammosphere/cancer stem cell (CSC) generation and tumorigenesis. Under $24 \mathrm{~h}$ serum starvation, $15.2 \%$ nominal retrotransposition frequency was increased to $29 \%$. Additionally, while treatment with 3-12 ng/ml VEGF further induced retrotransposition frequency in a dose-dependent manner (up to $40.3 \%$ ), pre-incubation with tinzaparin $(2 \mathrm{IU} / \mathrm{ml})$ for $0.5-4 \mathrm{~h}$ reduced this frequency to $18.3 \%$ in a time-dependent manner, confirmed by analogous results in NIH3T3 fibroblasts. Treatment with $10-40 \mathrm{pg} / \mathrm{ml}$ glucose oxidase (GO) for $24 \mathrm{~h}$ induced $\mathrm{HC} 11$ cell retrotransposition in a dose-dependent manner (up to $82.5 \%$ ), while a $3 \mathrm{~h}$ pre-incubation with tinzaparin ( 1 or $2 \mathrm{IU} / \mathrm{ml})$ elicited a 13.5 or $25.5 \%$ reduction in retrotransposition, respectively. Regarding tumorigenic VL30 retrotransposition-positive HC11 cells, treatment with $2 \mathrm{IU} / \mathrm{ml}$ tinzaparin for 5 days reduced proliferation rate in a time-dependent manner (up to $25 \%$ ), and after 3 weeks, disaggregated soft agar-formed foci, as well
\end{abstract}

Correspondence to: Professor Theodore Tzavaras, Laboratory of General Biology, Faculty of Medicine, School of Health Sciences, University of Ioannina, University Campus, 45110 Ioannina, Greece E-mail: thtzavar@uoi.gr

Key words: tinzaparin, VL30 retrotransposition, breast cancer, HC11 mammary stem-like cells, cancer stem cells, cell proliferation, mammosphere disaggregation as low-adherent mammospheres, producing single mesenchymal-like cells with a $\sim 50 \%$ reduced retrotransposition. With respect to the VL30 retrotransposition mechanism: While $12 \mathrm{ng} / \mathrm{ml}$ VEGF increased the level of VL30 and endogenous reverse transcriptase (enRT) transcripts $\sim 1.41$ - and $\sim 1$.16-fold, respectively, subsequent tinzaparin treatment reduced both endogenous/ROS- and VEGF-induced levels 1.15- and 0.4 0 -fold (VL30) and 0.60- and 0.52-fold (enRT), respectively. To the best of our knowledge, these data demonstrate for the first time, the novel inhibition activity of tinzaparin against ROS- and VEGF-induced VL30 retrotransposition, and the proliferation and/or aggregation of mouse HC11 mammosphere/tumor-initiating CSCs, thus contributing to the inhibition of VL30 retrotransposition-induced primary tumor growth.

\section{Introduction}

The association between thrombosis and cancer is well established; $25 \%$ of patients with cancer suffer from venous thromboembolic complications, the second most common cause of cancer-related death (1). Low molecular weight heparins (LMWHs) are currently used for antithrombotic treatment $(2,3)$; antithrombin limits the coagulation process, while its anticoagulant activity is stimulated by heparin (4). Tinzaparin is a LMWH-anticoagulant used for the treatment of deep vein thrombosis (5), and is recommended for optimum antithrombotic interventions in the secondary prophylaxis of cancer patients (6) with renal failure (7) and brain tumors (8). Several studies (9-17), reviewed for experimental models (18), have shown the anticancer properties of tinzaparin However, in local tumor growth, tinzaparin failed to impede cellular proliferation in an in vitro model of human breast cancer cells (11). Furthermore, it has been reported that tinzaparin has no effect on primary tumor growth in the B16F10 metastasis model, and that non-anticoagulant heparin inhibits metastasis, but not primary tumor growth (19). 
Tumor growth and metastatic potential are angiogenesis-dependent (20), and VEGF is a major angiogenic growth factor involved in human tumors and angiogenic diseases (21). In addition to the potent inhibition of angiogenesis (15), tinzaparin also has an important effect on tumorigenesis and metastasis. Specifically, in the B16 melanoma-injectable model of metastasis, treatment of mice with tinzaparin for 4 $\mathrm{h}$ prior to injection of melanoma cells, or daily administration for 14 days, was shown to reduce lung tumor formation by 89 and $96 \%$, respectively (14). Furthermore, tinzaparin has been reported to inhibit the extracellular vesicle-induced migration of carcinoma cells (22), as well as pancreatic tumor growth and metastasis (23). Finally, tinzaparin also has effects at the nuclear level, modulating (among other diverse processes) the expression of genes that regulate transcription and chromatin modification in human A2780cis ovarian cancer cells; notably, tinzaparin treatment caused marked transcriptional reprogramming of 3,776 tinzaparin-regulated genes, and antagonized cisplatin-resistance (17).

Epithelial-mesenchymal transition (EMT) is an important process involved in cancer progression, influencing cellular invasion and metastasis. During EMT, epithelial cells lose polarity and cell-to-cell contact, which is accompanied by cytoskeleton remodeling, and the acquisition of migratory properties, as well as a mesenchymal-like profile of gene expression $(24,25)$. In addition to the induction of angiogenesis, VEGF also induces EMT in human pancreas carcinoma cells (26). Strong evidence suggests a link between EMT and cancer stem cells (CSCs) $(27,28)$, and human breast tumors characterized by a small population of CSCs are also termed as tumor-initiating cells (29). Furthermore, a number of EMT-related properties of CSCs have been shown to be associated with the establishment of breast cancer metastasis (27).

Retrotransposons are DNA sequences that constitute $\sim 45 \%$ of the human and mouse genome, and play a crucial role in nuclear organization, structure and evolution (30). Categorized as long terminal repeat (LTR) and non-LTR subtypes, retrotransposons are mobilized in the genome by the intracellular process of retrotransposition. LTR retrotransposition requires a retrotransposon RNA-intermediate, which upon reverse transcription to cDNA, is integrated into a new genomic site (31). Retrotransposition is a potent mutagenic phenomenon, as new retrotransposon copy integrations can inactivate or deregulate the expression of nearby genes. Currently, 124 independent retrotransposon insertions have been correlated with 65 human diseases, including cancer (32). Retrotransposition is a rare phenomenon that occurs at a low frequency of up to $10^{-6}$ events/cell in each cell generation (33). Low-rate retrotransposition events mainly occur during oogenesis and embryogenesis $(34,35)$, while induced or uncontrolled retrotransposon mobility occasionally result in the onset of genetic diseases or tumorigenesis (35).

VL30 elements (VL30s) are a family of endogenous retrovirus-like LTR-retrotransposons, present in the mouse and rat genomes. Their internal sequences bear multiple stop codons, and with a lack of protein coding capacity (36), VL30s are non-infectious. VL30 transcripts form a complex with the poly-pyrimidine tract binding protein-associated splicing factor (PSF), and upregulate gene expression and proto-oncogene transcription, as well as affecting embryo- genesis and steroidogenesis (37). Furthermore, the PSF/VL30 RNA complex promotes cellular proliferation and oncogenesis (37). VL30 LTRs bear a large number of common and unique transcription factor binding sites, which may justify the versatile and tissue-specific expression of VL30 RNA, as well as its upregulation by various or pleiotropic stimuli, respectively (38) (for example; histone phosphorylation, acetylation and DNA demethylation) (39). VL30 transcription is also induced by the Simian virus 40 large $T$ antigen (40) and heavy metals $(41,42)$, as well as steroid hormones, 5'-azacytidine, C2-ceramide and a mouse dominant-negative p53 gene (43). Transcriptional induction by various inducers is a prominent feature of VL30s, classified as early response genes (36). In reference to the mutagenic or deleterious effects of retrotransposition, induction of VL30 retrotransposition has been associated with cytotoxicity (44) and cell death (45). Notably, our previous study revealed VL30 retrotransposition induced by either arsenic (42) or $\mathrm{H}_{2} \mathrm{O}_{2}$ (44) is effectively reduced by the anti-oxidant $\mathrm{N}$-acetylcysteine (NAC).

Previously, VL30 retrotransposition in mouse HC11 epithelial mammary cells (with stem-like properties) was reported in association with induced EMT, CSC generation and tumor growth (46). Since tinzaparin modulates the expression of a large number of genes (17), and LTR-retrotransposition is accomplished through a retrotransposon RNA-intermediate, the aim of the present study was to establish whether tinzaparin also affected VL30 retrotransposition. Applying a previous model of HC11/VL30 retrotransposition (40), the current study indicates novel activities of tinzaparin as an anti-oxidant, anti-VEGF and anti-retroviral agent for the inhibition of VL30 retrotransposition. Furthermore, tinzaparin was shown to cause both disaggregation and proliferative inhibition of VL30 retrotransposition-induced mammosphere/tumor-initiating CSCs, suggesting an inhibition of VL30 retrotransposition-induced tumorigenesis.

\section{Materials and methods}

Cell lines, cloning and treatments. HC11 cells are immortalized mouse mammary epithelial cells (47) originating from mid-pregnancy BALB/c mice, with stem-like or progenitor cell properties (48). HC11 cells were cultured in RPMI 1640 medium containing 10\% FBS, 2 mM L-glutamine, $5 \mathrm{mg} / \mathrm{ml}$ insulin, $10 \mathrm{ng} / \mathrm{ml}$ EGF (47), 100 units penicillin and $100 \mu \mathrm{g} / \mathrm{ml}$ streptomycin (all Thermo Fisher Scientific, Inc.) at $37^{\circ} \mathrm{C}$ in an incubator supplemented with $5 \% \mathrm{CO}_{2}$. A total of $2.5 \times 10^{5} \mathrm{HC} 11$ cells were transfected at room temperature with $2.5 \mu \mathrm{g}$ of our previously constructed pNVL-3*/EGFP-INT DNA (40) using the PolyFect ${ }^{\circledR}$ transfection reagent (Qiagen, Inc.), and then cultured for $16 \mathrm{~h}$ under cell culture conditions. Hygromycin B-resistant cell clones were isolated following application of $100 \mu \mathrm{g} / \mathrm{ml}$ hygromycin B for 18 days. Isolated clone cells were further cultured for 20 days in cell culture treated flasks (Corning, Inc.), and used for subsequent experimentation. Notably this plasmid harbors a recombinant VL30 element tagged with an EGFP gene-based retrotransposition indicator cassette, and the expression of EGFP protein occurs solely after a retrotransposition event. Thus, VL30 retrotransposition-positive cells can be enumerated by flow cytometry (40). Our previously isolated Pcl.10 cell clone 
derived from NIH3T3 mouse embryo fibroblasts transfected with pNVL-3*/EGFP-INT (40), as aformentioned. Pcl.10 cells were cultured in Dulbecco's modified Eagle's medium (DMEM) supplemented with 10\% FBS, $2 \mathrm{mM}$ glutamine and antibiotics (100 units penicillin and $100 \mu \mathrm{g} / \mathrm{ml}$ streptomycin, and maintained as aforementioned. Serum starvation was performed in serum-free medium for $24 \mathrm{~h}$ at $37^{\circ} \mathrm{C}$. Recovery of $30 \%$ confluency $\mathrm{HC} 11$ cells treated with 1- or 2 IU tinzaparin pre-incubation for $3 \mathrm{~h}$, and $/$ or $40 \mathrm{pg} / \mathrm{ml}$ glucose oxidase (GO) for $24 \mathrm{~h}$, was performed by washing the cells twice with RPMI 1640 medium at room temperature. Tinzaparin sodium (syringe 10,000 anti-factor Xa IU/ml) was obtained from LEO Pharma A/S, and appropriate dilutions were made with culture medium. VEGF treatment at 3-12 $\mathrm{ng} / \mathrm{ml}$ was performed in both $\mathrm{HC} 11$ and Pcl.10 cells with mouse recombinant VEGF A (ImmunoTools GmbH) $24 \mathrm{~h}$ after serum starvation. Tinzaparin and/or VEGF treatment was performed at $37^{\circ} \mathrm{C}$.

Paraformaldehyde fixation and observation of EGFP/VL30 retrotransposition-positive cells. $\mathrm{HC} 11 \mathrm{cl} .11$ assay cells cultured at the desired confluence on sterilized glass coverslips were fixed with $3.7 \%$ paraformaldehyde for $30 \mathrm{~min}$ on ice. Then coverslip-samples mounted onto microscope slides were observed and photographed under normal or UV light (Nikon Eclipse E800 Fluorescent Microscope).

Measurement of VL30 retrotransposition frequency and cellular proliferation. All tested hygromycin B-resistant HC11 clone cells were trypsinized, washed with PBS, centrifuged at $1,600 \mathrm{x}$ g for $3 \mathrm{~min}$ at room temperature, and resuspended in PBS. Samples of 15,000 clone or non-transfected cells (as the negative control) were used to determine EGFP-positivity by flow cytometry, as previously described (40). The fluorescence intensity thresholds were evaluated using non-transfected cells, and sample fluorescence $\geq 99.60 \%$ was considered as negative, and $0.4 \%$ as false positive. Above the false-positive threshold, samples were considered as EGFP- or VL30 retrotransposition-positive. The continuous cell proliferation rate (cell index) was measured using a microelectronic biosensor system (xCELLigence ${ }^{\circledR}$ real-time cell analysis DP) in E-plates using 3,500 seeded cells in a volume of $60 \mu \mathrm{l}$ RPMI (supplemented with 10\% FBS) for up to $80 \mathrm{~h}$. Cellular proliferation was assessed by seeding 60,000 cells per well ( $\sim 10 \%$ confluent) into a 6 -well plate. Cells from three wells were trypsinized, stained with trypan blue and counted using a Neubauer hemocytometer every $24 \mathrm{~h}$ for a period of 5 days (44).

Soft agar-foci formation assay. The foci formation assay was based on a previously described protocol (49). Briefly, 6-well plates bearing a $0.66 \%$ nobble agar-base layer (prepared in $10 \% \mathrm{FBS} / \mathrm{RPMI}$ medium supplemented with 100 units penicillin and $100 \mu \mathrm{g} / \mathrm{ml}$ streptomycin), a $0.33 \%$ upperand $0.33 \%$ feeder layer, were used. The upper layer was prepared after mixing nobble agar with trypsinized cells from either control or test cell groups, in the presence or absence of $2 \mathrm{IU} / \mathrm{ml}$ tinzaparin, respectively. Dishes were incubated at $37^{\circ} \mathrm{C}$ in a $5 \% \mathrm{CO}_{2}$ cell culture incubator, and supplemented with $200 \mu \mathrm{l}$ medium every two days to avoid desiccation. The examination of dishes for cell foci was formation performed with an optical microscope.

Mammosphere preparation from tumorigenic HC11 cl.19 cells. For mammosphere preparation, VL30 retrotranspositiontumorigenic $\mathrm{HC} 11$ cl.19 cells cultured in normal culture plates were trypsinized and seeded into non-adherent plates at $30 \%$ density. Following 20 days of culture, the cells were replenished with RPMI-1640 medium every 2 days, and the resulting anchorage-independent/floating mammospheres in the culture medium were collected using a pipette for further use.

DNA lysate preparation and PCR analysis. A total of $1.5 \times 10^{6} \mathrm{HC} 11$ cl.19 cells were trypsinized, washed with PBS and centrifuged at $1,600 \mathrm{x}$ g for $3 \mathrm{~min}$ at room temperature. Cell pellets were resuspended in $800 \mu$ PCR wash buffer [10 mM Tris- $\mathrm{HCl}$ (pH 8.4), $50 \mathrm{mM} \mathrm{KCl,} 1.5 \mathrm{mM} \mathrm{MgCl}_{2}$ and $0.001 \%(\mathrm{w} / \mathrm{v})$ gelatin], and centrifuged once more. The pellets were then gently resuspended in $100 \mu 1 \mathrm{PCR}$ lysis buffer [10 mM Tris-HCl pH 8.4, $50 \mathrm{mM} \mathrm{KCl}, 1.5 \mathrm{mM} \mathrm{MgCl}_{2}$, $0.001 \%$ gelatin, $0.1 \%$ (v/v) Triton X-100, $0.45 \%$ (v/v) Nonidet $\mathrm{P}-40$ and $0.45 \%(\mathrm{v} / \mathrm{v})$ Tween-20], heated at $80^{\circ} \mathrm{C}$ for $10 \mathrm{~min}$, cooled at room temperature for $15 \mathrm{~min}$ and then treated with $4 \mu \mathrm{l}$ proteinase $\mathrm{K}(10 \mathrm{mg} / \mathrm{ml})$ overnight at $55^{\circ} \mathrm{C}$. Following heat inactivation at $95^{\circ} \mathrm{C}$ for $15 \mathrm{~min}$, the samples were centrifuged at $1,600 \mathrm{xg}$ for $3 \mathrm{~min}$ at room temperature, and the supernatant, representing an extracted DNA lysate, was collected. A volume of 3-5 $\mu \mathrm{l}$ DNA lysate was used for PCR analysis. PCR reactions were performed using 2.5 units Taq polymerase (Invitrogen; Thermo Fisher Scientific, Inc.) in a final volume of $50 \mu \mathrm{l}$, with specific EGFP primers: GFP968 forward, 5'-GCA CCATCTTCTTCAAGGACGAC-3', and GFP1013 reverse, 5'-TCTTTGCTCAGGGCGGACTG-3' (50) using conditions previously reported (40).

Semi-quantitative reverse transcription (RT)-PCR analysis. Quantitation of endogenous reverse transcriptase (enRT) and VL30 transcripts was performed by RT-PCR. Total RNA was extracted from untreated cells, cells treated with VEGF alone or VEGF/tinzaparin using a RNeasy Mini Kit (Qiagen, Inc.). Subsequently, $100 \mathrm{ng}$ cDNA was prepared from $1 \mu \mathrm{g}$ total RNA. A set of degenerate primers designed to target the enRT conserved domains (4 and 5 amino acid sequences identified in the amino-terminal coding regions of most known enRT polymerases including that of the Moloney murine leukemia virus) (51), as well as a set of previously reported VL30-specific primers: Forward, 5'-CCTTTGTTGCCCAGG TAAGTC-3' and reverse, 5'-CACTGTAGCCAGTTGTGA CCAG-3' (52). mRNA expression of the mouse $\beta$-actin gene was quantitated using the following primers: $\beta$-actin forward, 5'-TTGCTGACAGGATGCAGAAG-3' and reverse, 5'-ACA TCTGCTGGAAGGTGGAC-3'. The enRT thermocycling conditions were as follows: $94^{\circ} \mathrm{C}$ for $4 \mathrm{~min} ; 27$ cycles of $94^{\circ} \mathrm{C}$ for $30 \mathrm{sec}, 50^{\circ} \mathrm{C}$ for $45 \mathrm{sec}$, and $72^{\circ} \mathrm{C}$ for $2 \mathrm{~min}$; and $72^{\circ} \mathrm{C}$ for $2 \mathrm{~min}$. The VL30 thermocycling conditions were: $94^{\circ} \mathrm{C}$ for $4 \mathrm{~min} ; 30$ cycles of $94^{\circ} \mathrm{C}$ for $30 \mathrm{sec}, 57^{\circ} \mathrm{C}$ for $30 \mathrm{sec}$ and $72^{\circ} \mathrm{C}$ for $2 \mathrm{~min}$; and $72^{\circ} \mathrm{C}$ for $2 \mathrm{~min}$. Finally, the $\beta$-actin conditions were: $94^{\circ} \mathrm{C}$ for $4 \mathrm{~min} ; 27$ cycles of $94^{\circ} \mathrm{C}$ for $30 \mathrm{sec}, 57^{\circ} \mathrm{C}$ for $30 \mathrm{sec}$, and $72^{\circ} \mathrm{C}$ for $1.5 \mathrm{~min}$; and $72^{\circ} \mathrm{C}$ for $2 \mathrm{~min}$. All PCR 
products were fractionated using $1.2 \%(\mathrm{w} / \mathrm{v})$ agarose gels, stained with ethidium bromide (EtBr), and visualized under ultraviolet light. enRTs and VL30 RNA expression values were normalized to that of $\beta$-actin, and densitometric analysis was performed using Fiji (ImageJ2) software (National institutes of Health).

Statistical analysis. Statistical analysis was performed using GraphPad Prism version 5.0 (GraphPad Software, Inc.). Comparisons between multiple groups of retrotransposition frequency values were determined by one-way ANOVA followed by the Tukey's post hoc-test. A paired Student's t-test was used to assess statistically significant differences between two groups. $\mathrm{P}<0.05$ was considered to indicate a statistically significant difference.

\section{Results}

Isolation and characterization of VL30 retrotransposition-positive HC11 clones. In a previous study, VL30 retrotransposition-positive $\mathrm{HC} 11$ cell clones were generated, exhibiting an induced EMT phenotype, CSC properties and solid tumor production in syngeneic Balb/c mice (46), and with a retrotransposition frequency of $\sim 2-5.5 \%$. Notably, as HC11 cells possess stem-like properties, the occurrence of retrotransposition events could be explained by their hypomethylation status (46), as has been suggested for human stem cells (53). To examine the effect of tinzaparin and/or VEGF treatment on VL30 retrotransposition, new clones were isolated with a retrotransposition frequency of 7-15\%, allowing a more accurate measurement of retrotransposition changes, especially in the case of inhibition.

Following transfection with pNVL-3*/EGFP-INT, 20 hygromycin B-resistant $\mathrm{HC} 11$ clones were isolated. Using non-transfected $\mathrm{HC} 11$ cells as the control, the isolated clones were flow cytometrically examined for retrotransposition positivity, as exemplified for clone 11 (Figs. S1A and S2). Among all clones examined, a set of seven clones (cl.) exhibited the following percentages of retrotransposition frequency: $\mathrm{cl} .12,7 \%$; cl.15, 8\%; $\mathrm{cl} .6$ and cl.9, 9\%; cl.11, 11.5\%; cl.5, 12\%; and cl.17, 15.2\%, falling within the range of 7-15.2\% (Fig. S1B). PCR analysis confirmed retrotransposition-positivity at the genomic level in four representative clones, through the diagnostic intron-less $342 \mathrm{bp}$ band [indicative of a retrotransposition event (40) (Fig. S1C)]. Furthermore, microscopic observation revealed two common VL30 retrotransposition-derived features, as shown for representative cl.11 (Fig. S3): i) An expected VL30 retrotransposition-induced EMT phenotype (46) observed at low confluence (Fig. S3B); and ii) cytoplasmic EGFP fluorescence (Fig. S3D), confirming the occurrence of VL30 retrotransposition events (40), associated with genomic instability manifested by multinucleated cells bearing enlarged cytoplasm, in cell clusters formed at high confluence (Fig. S3C). Thus, isolated clones with a retrotransposition value of 7-15.2\% may be used for studying factors that modulate the frequency of VL30 retrotransposition.

Tinzaparin inhibits VEGF-induced VL30 retrotransposition in HC11 cells. To address the potential role of VEGF and/or tinzaparin treatment on VL30 retrotransposition,
HC11 cl.17 cells were initially cultured in serum-free medium for $24 \mathrm{~h}$ to exclude the presence of serum associated-VEGF. Following serum starvation for $24 \mathrm{~h}$, (a condition used in all subsequent treatments), the retrotransposition frequency of HC11 cl.17 cells was increased from 15.2 to $29 \%$ (Fig. 1A). Then, HC11 cl.17 cells were serum-starved in the absence or presence of 3,6 or $12 \mathrm{ng} / \mathrm{ml} \mathrm{VEGF}$ for $24 \mathrm{~h}$ and their retrotransposition was compared with serum-starved cells without VEGF as the control, VEGF treatment increased retrotransposition in a dose-dependent manner in all cases (Fig. 1A). The level of retrotransposition under serum starvation $(29 \%)$ increased in the presence of increasing VEGF concentrations $(3,6$ and $12 \mathrm{ng} / \mathrm{ml})$ to $30.4,33.4$ and $40.3 \%$ corresponding to a net VEGF-dependent induction of $1.4,4.4$ and $11.3 \%$, respectively.

To investigate the action of tinzaparin on VEGF-induced VL30 retrotransposition, serum-starved cells were initially pre-incubated with $2 \mathrm{IU}$ tinzaparin/ml for $4 \mathrm{~h}$, and then treated, in the presence of tinzaparin, with 3,6 or $12 \mathrm{ng} / \mathrm{ml}$ VEGF for $24 \mathrm{~h}$. Compared with those treated with VEGF alone, the retrotransposition frequencies of tinzaparin/VEGF-treated samples were significantly reduced. Specifically, at 3, 6 and $12 \mathrm{ng} / \mathrm{ml} \mathrm{VEGF,} \mathrm{tinzaparin} \mathrm{reduced} \mathrm{retrotrans-}$ position frequency from 30.4 to $28.7 \%, 33.4$ to $24.6 \%$, and 40.3 to $18.3 \%$, respectively, corresponding to a net reduction in retrotransposition frequency of 1.7, 8.8 and $22 \%$ (Fig. 1A).

Next, the effects of tinzaparin pre-incubation time on the inhibition of retrotransposition were assessed using treatment times $<4 \mathrm{~h}$. HC11 cl.17 cells were pre-incubated with 2 IU tinzaparin/ml for $0.5,1,2$ or $4 \mathrm{~h}$, and then treated with $12 \mathrm{ng} / \mathrm{ml}$ VEGF for $24 \mathrm{~h}$. Using the $39.42 \%$ retrotransposition frequency of tinzaparin-untreated cells as the control, tinzaparin reduced VEGF-induced retrotransposition frequency in a time-dependent manner (Fig. 1B). At 0.5, 1, 2 and $4 \mathrm{~h}$, respective retrotransposition frequencies of $36.1,32.2,26.3$ and $18.7 \%$ were recorded, corresponding to a net inhibition of 8.37, 18.27, 33.24 and $52.53 \%$.

In preliminary experiments, a higher concentration of VEGF (i.e. 15 compared with $12 \mathrm{ng} / \mathrm{ml}$ ) induced an even greater retrotransposition frequency than the $40.3 \%$ presented in Fig. 1 (data not shown). It was concluded that: i) $40.3 \%$ induced retrotransposition was suitable enough to reliably document the effects of tinzaparin with VEGF treatment; and ii) such a high value $(40.3 \%)$ was adequate to more accurately assess the effectiveness of tinzaparin, especially at low concentrations (such as the 1 or 2 IU used), and to retain $\mathrm{HC} 11$ cell functionality at this level of VEGF-derived retrotransposition, as a higher VEGF concentration may induce many more mutations [since $1 \%$ induced retrotransposition equates to an additional 'retrotransposition burden' of 1000-fold genome-mutations/cell (33)]. Collectively, these data revealed that tinzaparin was effective in simultaneously reducing serum-starved/VEGF-induced VL30 retrotransposition.

Tinzaparin inhibits VEGF-induced VL30 retrotransposition in NIH3T3 cells. The aforementioned data prompted the investigation of VEGF and/or VEGF/tinzaparin treatment on cell types other than epithelial HC11 mammary progenitors. A previously generated VL30 retrotransposition-positive clone (Pcl.10), derived from mouse NIH3T3 fibroblast cells, 
A

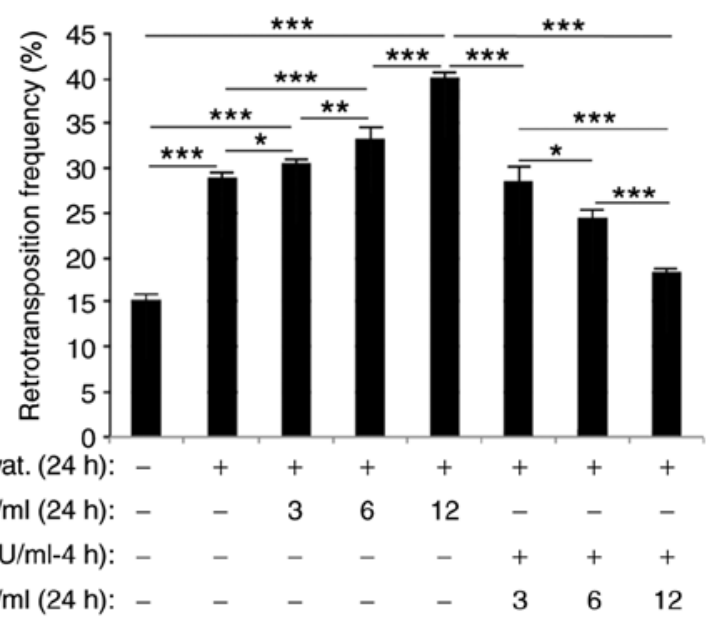

B

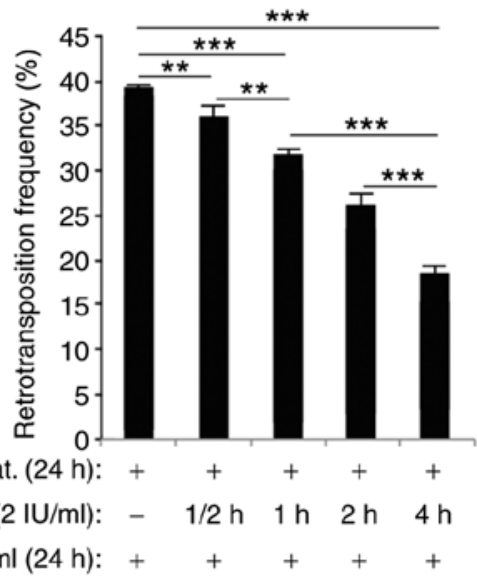

Figure 1. Tinzaparin inhibits serum starved- and VEGF-induced VL30 retrotransposition. (A) Retrotransposition-positive HC11 cl.17 cells were either untreated; serum starved and treated with VEGF; or serum starved, pre-incubated with tinzaparin and then treated with VEGF. (B) Retrotransposition-positive HC11 cl.17 cells were either serum starved and treated with VEGF, or serum starved, pre-incubated with tinzaparin and then treated with VEGF. Data are presented as the mean $\pm \mathrm{SD}$, duplicate samples from three independent experiments. ${ }^{*} \mathrm{P}<0.05,{ }^{* *} \mathrm{P}<0.01$ and ${ }^{* * *} \mathrm{P}<0.001$; one-way $\mathrm{ANOVA}$ followed by Tukey's test. Ser. starvat, serum starvation; Tinz, tinzaparin.

was used. Notably, Pcl.10 is a hygromycin B-resistant NIH3T3 fibroblast clone, isolated as HC11 clones, but VL30 retrotransposition events are elicited solely following a stimulus such as the SV40 large T antigen (40), heavy-metal vanadium $\left(\mathrm{VOSO}_{4}\right)$ (41) or arsenic (42). Serum starvation for $24 \mathrm{~h}$ induced VL30 retrotransposition frequency by $2.4 \%$, compared with non-serum starved Pcl.10 cells. Furthermore, treatment with $12 \mathrm{ng} / \mathrm{ml}$ further increased retrotransposition frequency to $7.44 \%$ (Fig. S4), corresponding to a net increase of $5.04 \%$. Notably, VEGF concentrations up to $50 \mathrm{ng} / \mathrm{ml}$ did not increase retrotransposition frequency further (data not shown). Then, Pcl.10 cells were pre-incubated with $2 \mathrm{IU}$ tinzaparin $/ \mathrm{ml}$ for $0.5,1,2$ or $4 \mathrm{~h}$, and then treated with $12 \mathrm{ng} / \mathrm{ml} \mathrm{VEGF}$ for $24 \mathrm{~h}$. Of note, $7.44 \%$ VEGF-induced retrotransposition frequency (used as control), was inhibited in a time-dependent manner to $6.5,4.75,3.8$ and $2.45 \%$, respectively (Fig. S4). The use of Pcl.10 cells showed that the reduction of VEGF-induced retrotransposition by tinzaparin is not limited to mouse mammary epithelial stem-like HC11 cells.

Tinzaparin inhibits oxidative stress-induced VL30 retrotransposition in HC11 cells. Serum starvation has been reported to induce the production of reactive oxygen species (ROS) in prostate cancer cell lines (54), and our previous study showed that $\mathrm{H}_{2} \mathrm{O}_{2}$-derived oxidative stress induces VL30 retrotransposition of NIH3T3 fibroblast Pcl.10 clone cells to a high level (44). Therefore, the effect of oxidative stress on HC11 retrotransposition, and whether it is affected by tinzaparin treatment, was investigated in the present study. VL30 retrotransposition signals activation of a caspase-independent and p53-dependent death pathway (45), while HC11 cells, harboring a mutated p53 gene (55), alleviated cell death allowing the measurement of high retrotransposition frequencies.

In the present study, HC11 cl.17 cells (Fig. S1B) were initially treated with $5-40 \mathrm{pg} / \mathrm{ml} \mathrm{GO}$ for $24 \mathrm{~h}$, and retrotransposition frequency was measured after a $48 \mathrm{~h}$ recovery in normal medium, using non-treated cells as the control. At
10-40 pg/ml GO, the $15.2 \%$ nominal retrotransposition frequency of $\mathrm{HC} 11 \mathrm{cl} .17$ cells was further increased in a concentration-dependent manner, up to $\sim 82.5 \%$ at $40 \mathrm{pg} / \mathrm{ml}$ (Fig. 2A). Next, considering that $40 \mathrm{pg} / \mathrm{ml} \mathrm{GO}$ strongly induced VL30 retrotransposition, HC11 cl.17 cells were pre-incubated with 1 or $2 \mathrm{IU} / \mathrm{ml}$ tinzaparin for $3 \mathrm{~h}$, then treated with $40 \mathrm{pg} / \mathrm{ml}$ GO for $24 \mathrm{~h}$. Pre-incubation with $1 \mathrm{IU}$ - or $2 \mathrm{IU} / \mathrm{ml}$ tinzaparin reduced the $\sim 82.5 \%$ GO-induced retrotransposition frequency to respective values of 69 and $57 \%$, corresponding to a 13.5 or $25.5 \%$ level of inhibition (Fig. 2B). The data indicate that tinzaparin, reducing GO-induced retrotransposition, acts as an anti-oxidant agent.

Tinzaparin inhibits CSC features of VL30 retrotranspositionpositive HC11 cells. Our previous study reported that VL30 retrotransposition-positive $\mathrm{HC} 11$ cells acquire tumorigenic features such as a high rate of proliferation, induced-EMT phenotype and anchorage-independent mammosphere formation (46). These findings prompted the investigation of tinzaparin on the features of VL30 retrotransposition-positive HC11 cells.

Using both the previously well-characterized HC11 cl.19 for its retrotransposition-induced CSCs and mammosphere formation properties (46), and $\mathrm{HC} 11$ cl.15 from the present study, the effect of tinzaparin on $\mathrm{HC} 11$ cell proliferation rate was initially examined. Trypsinized cells from these clones were subjected to real-time cell analysis in the absence or presence of $2 \mathrm{IU} / \mathrm{ml}$ tinzaparin for up to $80 \mathrm{~h}$, using normal HC11 cells as the control. In the absence of tinzaparin, the continuous proliferation rate of both retrotransposition-positive clones was markedly higher than that of the control cells, but was inhibited to varying degrees in the presence of tinzaparin (Fig. 3A). However, the tinzaparin-induced reduction of proliferation was retained up to $60 \mathrm{~h}$, as previously observed (46), most probably due to the continuous cell proliferation in the absence of culture media replenishment. To quantify the inhibitory effect of tinzaparin on cell proliferation at longer 
A

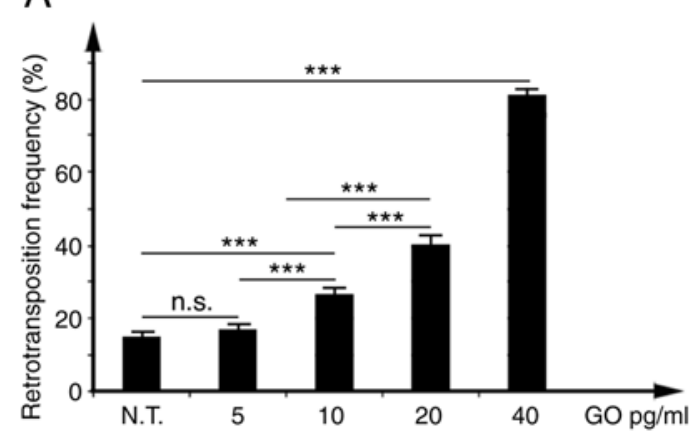

B

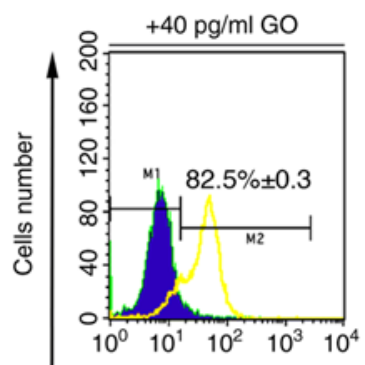

$3 \mathrm{~h}$ Tinzaparin pre-incubation:

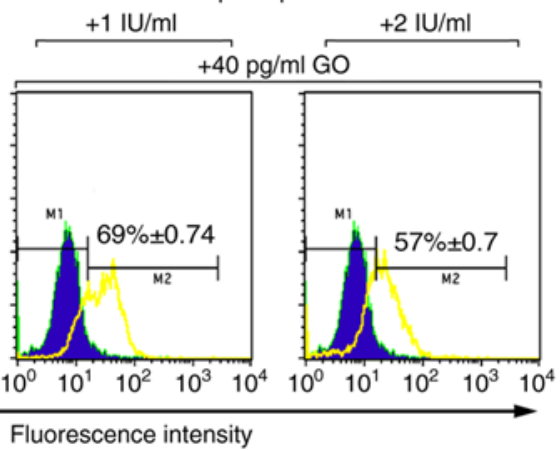

Figure 2. Tinzaparin inhibits the GO-induced VL30 retrotransposition frequency of HC11 cl.17 cells. (A) HC11 cl.17 cells, with a $15.2 \pm 0.3 \%$ nominal retrotransposition frequency, were treated with $5-40 \mathrm{pg} / \mathrm{ml} \mathrm{GO}$ for $24 \mathrm{~h}$, and retrotransposition frequency was measured by flow cytometry $48 \mathrm{~h}$ post-treatment recovery, using N.T. HC11 cl.17 cells as the control. Data are presented as the mean \pm SD, with duplicate samples from three independent experiments. ${ }^{* * * *} \mathrm{P}<0.001$; one-way ANOVA followed by Tukey's test. (B) HC11 cl.17 cells were either treated with 40 pg/ml GO for 24 h, or pre-incubated with 1- or 2 IU tinzaparin for $3 \mathrm{~h}$ and then treated with $40 \mathrm{pg} / \mathrm{ml} \mathrm{GO}$ for $24 \mathrm{~h}$. N.T. cells or treated cultures were assessed for EGFP-positivity by flow cytometry. Overlaid green circumscribed-solid blue and yellow histograms represent fluorescence of control and tinzaparin/GO-treated HC11 cl.17 cells, respectively. M1 and M2 gates correspond to arbitrarily set fluorescence intensity thresholds, up to $99.60 \%$ considered as negative and $0.4 \%$ false positive. The indicated percentage values with standard error \pm SE shown inside the histogram panels represent net retrotransposition frequencies, subtracting a $0.4 \%$ self-fluorescence percentage (false positive at M2). Percentage of retrotransposition values shown on the left, middle and right panels, respectively, are the mean \pm SE of duplicate samples from three independent experiments. GO, glucose oxidase; N.T., non-treated; n.s., not significant.

time-points, cells from each clone were cultured in the absence or presence of $2 \mathrm{IU} / \mathrm{ml}$ tinzaparin, and counted daily for 5 days. Tinzaparin inhibited the proliferation of both clones in a time-dependent manner, reaching up to $\sim 55$ and $\sim 60 \%$ for clones 19 and 15, respectively, at day 5 (Fig. 3Ba and b).

VL30 retrotransposition-positive $\mathrm{HC} 11$ clones produce CSCs forming anchorage-independent mammospheres (46); therefore their ability to produce cell foci in semi-solid media, and whether this is affected by tinzaparin, was assessed. Trypsinized cells from either normal HC11 or HC11 cl.19 cultures were maintained for three weeks in soft-agar plates containing normal RPMI medium. While normal HC11 cells were not capable of forming foci (Fig. 4, left panel), the respective $\mathrm{HC} 11 \mathrm{cl} .19$ cells produced large expanding foci (Fig. 4, middle panel). Furthermore, in the presence of $2 \mathrm{IU} / \mathrm{ml}$ tinzaparin, the resultant foci were smaller in size (Fig. 4, right panel).

Next, the effect of tinzaparin on mammosphere formation was investigated. HC11 cl.19 cells were seeded into normal culture dishes and their growth was monitored. 10 days after reaching full confluence, multinucleated cells bearing cytoplasmic vacuoles were observed, as well as cell clusters with emerging mammospheres (Fig. 5Aa, arrows). In parallel, examining growth in non-adherent culture dishes for 20 days, the formation of large spheroid cell masses, or mammospheres floating in the culture medium, was apparent (Fig. 5Ab). Next, selected mammospheres transferred into fresh dishes were further cultured in the presence of $2 \mathrm{IU} / \mathrm{ml}$ tinzaparin for two or three weeks. After two weeks of tinzaparin administration, substantially reduced mammosphere-size, accompanied by a small number of either disaggregated floating or single mammosphere cells attached to the culture dish, were observed (Fig. 5Ba and b). Notably, after three weeks, the effect of tinzaparin was augmented, as even smaller-sized mammospheres were observed, and the vast majority of single disaggregated mammosphere cells were attached to the dish, bearing a clear mesenchymal phenotype (Fig. 5Bc and d).
Since tinzaparin resulted in mammosphere disaggregation, the potential link between tinzaparin and the modulated retrotransposition of disaggregated cells was investigated. Compared with untreated HC11 cl.19 cells, the retrotransposition frequency of disaggregated HC11 cl.19 mammosphere-derived mesenchymal-like cells was assessed after treatment with 2 IU tinzaparin for 3 weeks. The retrotransposition frequency was reduced by $49.7 \%$ compared with the control, namely from their nominal $\mathrm{HC} 11$ cl.19 retrotransposition value of 21.1 , to $10.5 \%$ (Fig. 5C). Collectively, these data link the inhibitory effect of tinzapapin on VL30 retrotransposion frequency with the inhibition of cellular proliferation, reduction of cell foci size, and the disaggregation of mammospheres of tumorigenic VL30 retrotransposition-positive HC11 cells.

Tinzaparin inhibits the RNA expression of VL30s and endogenous reverse transcriptase retroviral genes. The retrotransposition of autonomous LTR-retrotransposons requires a retrotransposon RNA-intermediate, and the activity of a functionally self-encoded reverse transcriptase (31). To investigate the effect of tinzaparin on the inhibition of VL30 retrotransposition in HC11 cells, semi-quantitative RT-PCR analysis was used to quantity transcription of the retrotransposon RNA-intermediate and/or various enRT gene transcripts.

cDNAs were prepared from normal HC11 cl.19 cells used as control, as well as HC11 cl.19 cells treated with either tinzaparin or VEGF alone, or pre-incubated with tinzaparin and then treated with VEGF for $24 \mathrm{~h}$. Fractionation of PCR products revealed a primary $371 \mathrm{bp}$ band of transcriptionally active VL30s, as well as a smear of enRTs transcripts representing transcriptional active enRT genes, mostly in the range of 1,000-200 bp (Fig. 6A). While $2 \mathrm{IU} / \mathrm{ml}$ tinzaparin for $2 \mathrm{~h}$ had almost no effect on VL30 RNA expression, the relative expression of enRTs was inhibited $\sim 0.23$-fold in comparison to the control (arbitrarily considered as 1-fold). Notably, at 


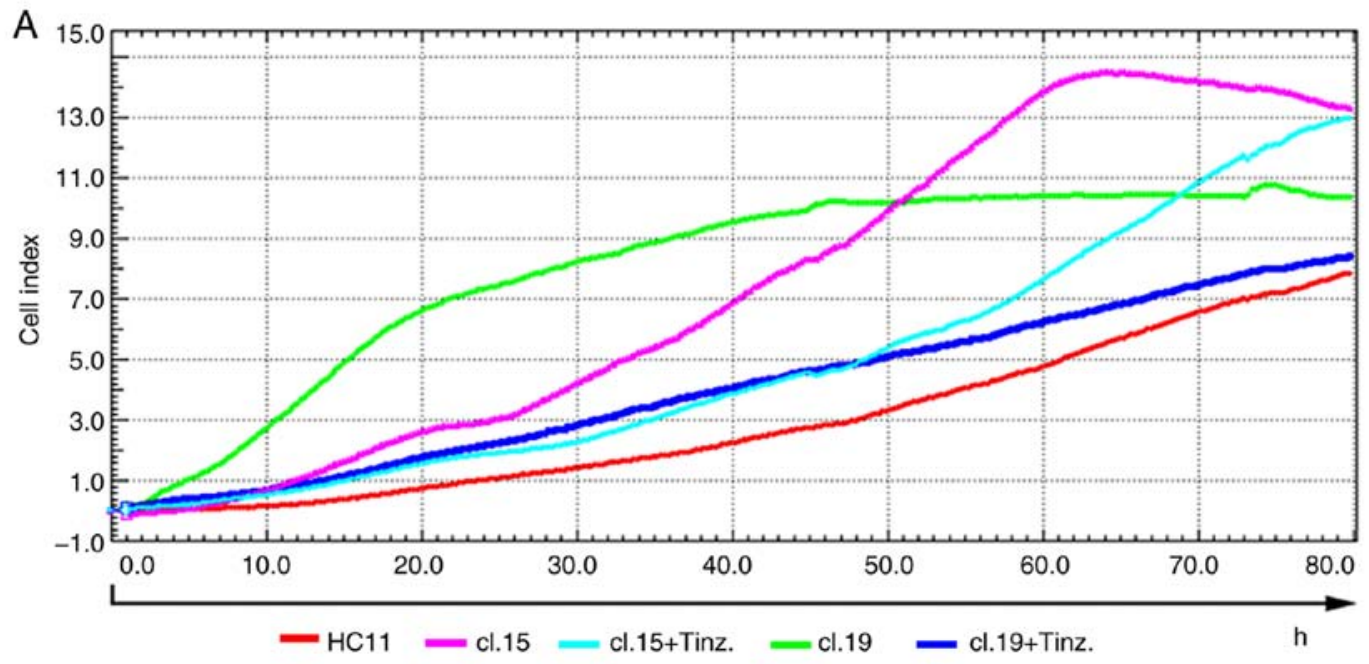

B a

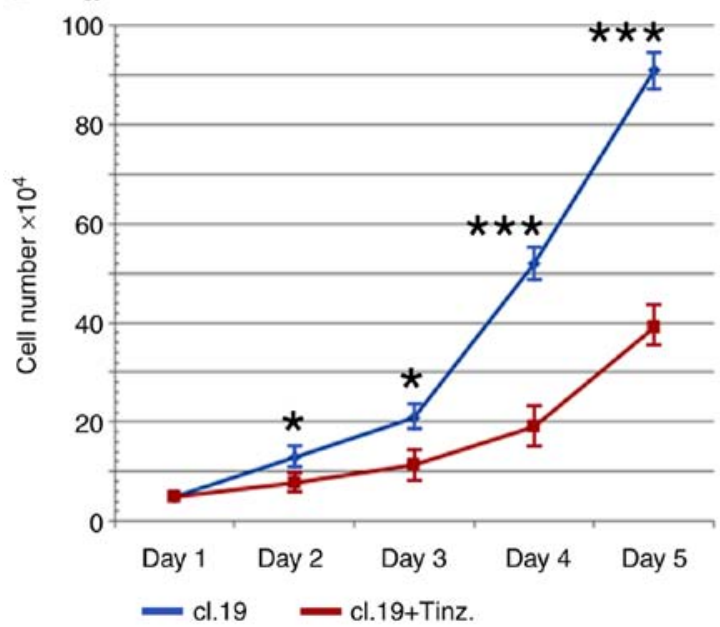

b

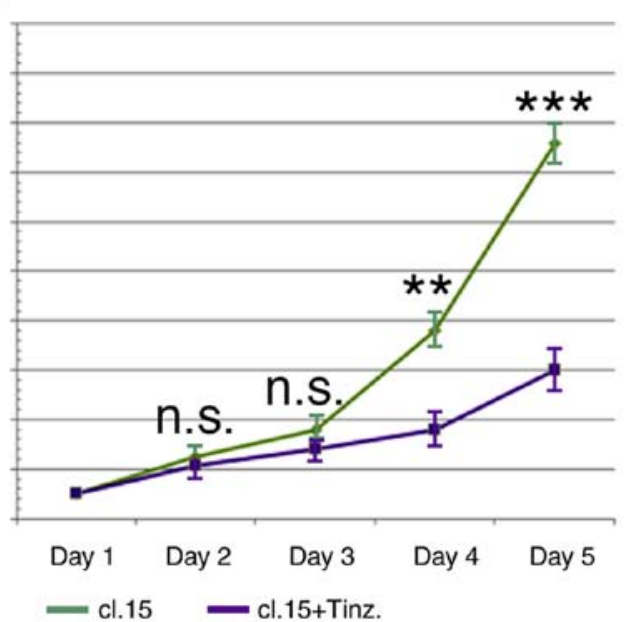

Figure 3. Tinzaparin decreases the proliferation rate of VL30 retrotransposition-positive HC11 cells. (A) Real-time cell analysis of tinzaparin-treated VL30 retrotransposition-positive $\mathrm{HC} 11$ cell proliferation. Normal HC11 (as the control), or $\mathrm{HC} 11$ cl.15 or cl.19 cells were cultured in the presence or absence of $2 \mathrm{IU}$ tinzaparin $/ \mathrm{ml}$, and continuous proliferation was recorded for an 80-h period. Cell index on the Y-axis refers to the cell proliferation rate. (B) Quantification of cell proliferation rate by hemocytometer. HC11 cl.19 or cl. 15 cells were treated with $2 \mathrm{IU}$ tinzaparin/ml for 5 days, and counted by hemocytometer. Cell number on each day is the mean $\pm \mathrm{SD}$ of three independent measurements from three experiments. ${ }^{*} \mathrm{P}<0.05,{ }^{* *} \mathrm{P}<0.01$ and ${ }^{* * * *} \mathrm{P}<0.001$. Tinz., tinzaparin; n.s., not significant.

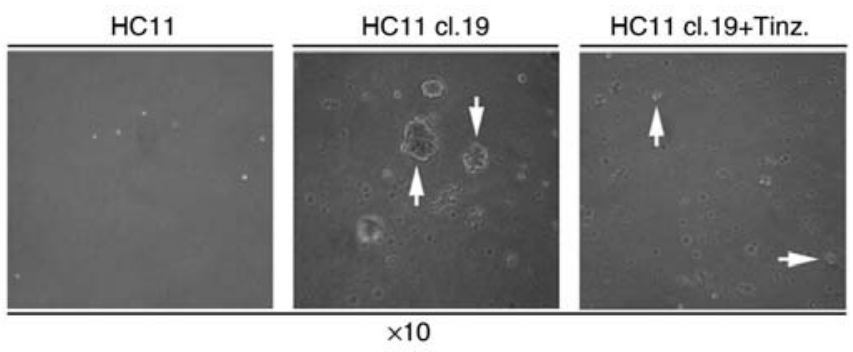

Figure 4. Tinz inhibits foci formation of tumorigenic VL30 retrotransposition-positive HC11 cells in semi-solid media. Petri dishes were prepared with an upper layer containing 400,000 cells deriving from either HC11 or HC11 cl.19 cells in the presence or absence of $2 \mathrm{IU} / \mathrm{ml}$ Tinz. Images captured after 3 weeks of culture (magnification, 10x) are representative of three respective samples. White arrows in the middle and right panels indicate large and small sized-cell foci, respectively. Tinz, tinzaparin.

$4 \mathrm{~h}$ of tinzaparin treatment, the RNA expression of VL30s was inhibited $\sim 1.15$-fold, while that of enRTs was further inhibited 0.40 -fold. Regarding cell treatment, $12 \mathrm{ng} / \mathrm{ml} \mathrm{VEGF}$ alone induced RNA expression of VL30s and enRTs of 1.41- and 1.16-fold. However, $4 \mathrm{~h}$ pre-incubation with $2 \mathrm{IU} / \mathrm{ml}$ tinzaparin, followed by $12 \mathrm{ng} / \mathrm{ml}$ VEGF, inhibited both relative RNA expression of VL30s and enRTs at the level of 0.60 - and 0.52 -fold, respectively, compared with control levels (Fig. 6A and B). Given that a $4 \mathrm{~h}$ tinzaparin pre-incubation simultaneously inhibited the VEGF-induced RNA expression of both VL30s and enRTs, the data indicate that tinzaparin acts rapidly as an anti-retroviral drug inhibiting the necessary VEGF-induced transcripts required for a retrotransposition event.

\section{Discussion}

The principal finding of the present study was the inhibitory effect of the angiogenic inhibitor tinzaparin (15) on VL30 retrotransposition, induced either by VEGF or oxidative stress, in mouse cells. VEGF-induced retrotransposition was documented using two different cell types: HC11 epithelial 
A

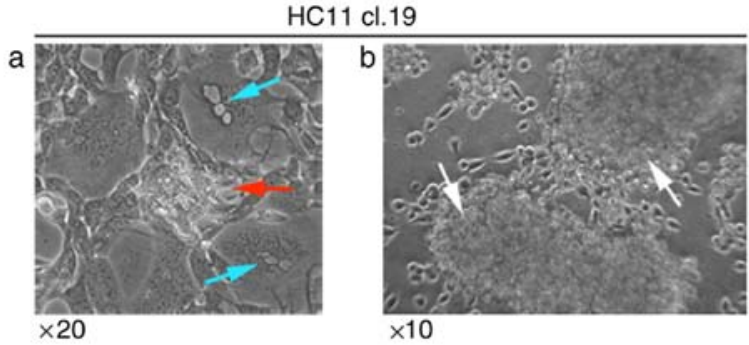

B
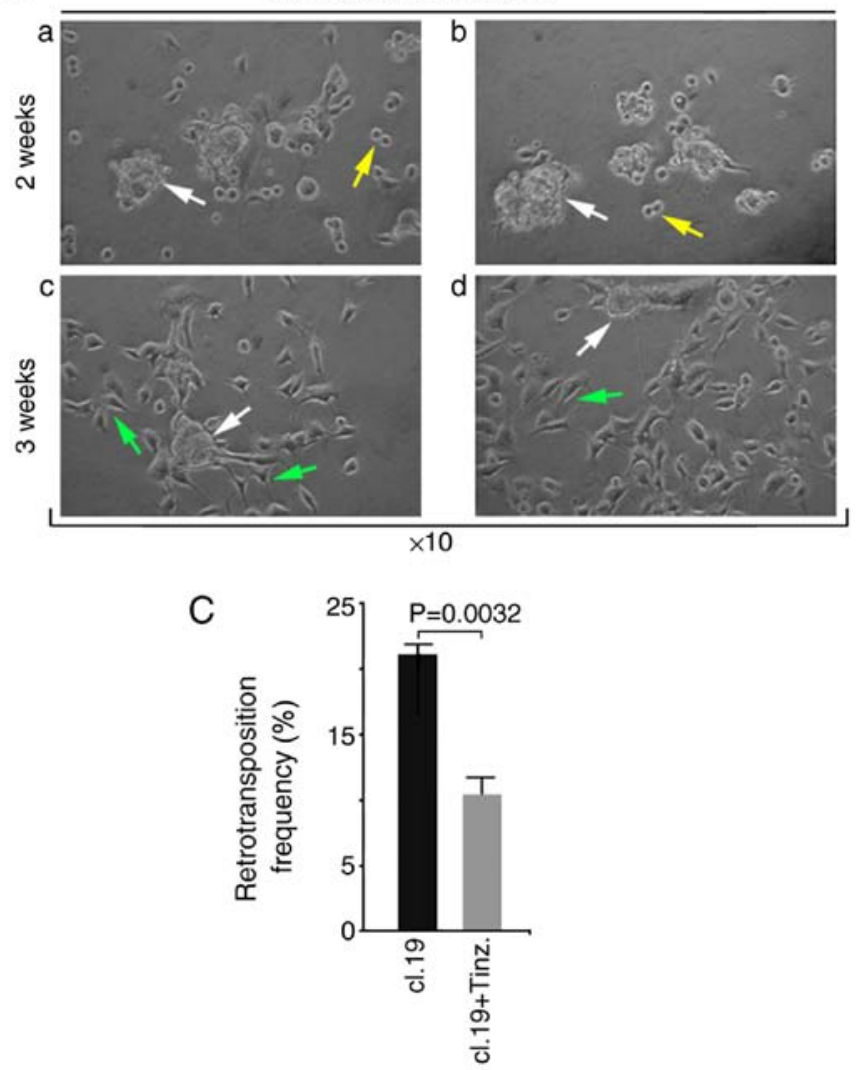

Figure 5. Tinz treatment elicits disaggregation of growing tumorigenic VL30 retrotransposition-positive $\mathrm{HC} 11 \mathrm{cl} .19$ mammospheres, and is associated with retrotransposition inhibition. (A) Confluent $\mathrm{HC} 11$ cl.19 cells were cultured for an additional 10 days in normal culture dishes (Aa) or for 20 days in non-adherent surface dishes (Ab). Red arrow in panel (Aa) shows outgrowth of a single early mammosphere, while turquoise arrows show multinucleated cells bearing cytoplasmic vacuoles. White arrows in panel (Ab) indicate growing mammospheres floating in the culture medium. Magnification, x20 and $x 10$ in panels (Aa) and (Ab), respectively. (B) Samples of pipette-collected floating mammospheres were further cultured in non-adherent surface dishes in the presence of $2 \mathrm{IU} / \mathrm{ml}$ tinzaparin either for two (panels $\mathrm{Ba} \& \mathrm{Bb}$ ) or three weeks (panels $\mathrm{Bc} \& \mathrm{Bd}$ ). White arrows in panels $\mathrm{Ba}, \mathrm{Bb}, \mathrm{Bc}$ and $\mathrm{Bd}$ indicate small-sized disaggregated mammospheres, while yellow arrows in $\mathrm{Ba} \& \mathrm{Bb}$ indicate single cells, and green arrows in $\mathrm{Bc} \& \mathrm{Bd}$, dish-attached mesenchymal-like cells. Magnification, x10. (C) Samples of cells from either non-treated $\mathrm{HC} 11 \mathrm{cl} .19$ cultures or disaggregated HC11 cl.19-mammosphere cells treated with 2 IU tinzaparin for 3 weeks, were flow cytometrically assessed for EGFP-positivity cells. Relative growth media of (B) and (C) assays, in the presence or absence of tinzaparin, were replenished every 3 days. Columns represent the mean value of retrotransposition frequencies $\pm \mathrm{SD}$, of duplicate samples from three independent experiments. Paired sample Student's t-test. Tinz., tinzaparin.

mammary stem-like cells and NIH3T3 fibroblasts. Serum starvation of HC11 cl.17 cells (Fig. S1B) increased their nominal retrotransposition value (15.2\%) to $29 \%$ (Fig. 1A). In addition, this frequency (in the absence of serum-containing VEGF)
A

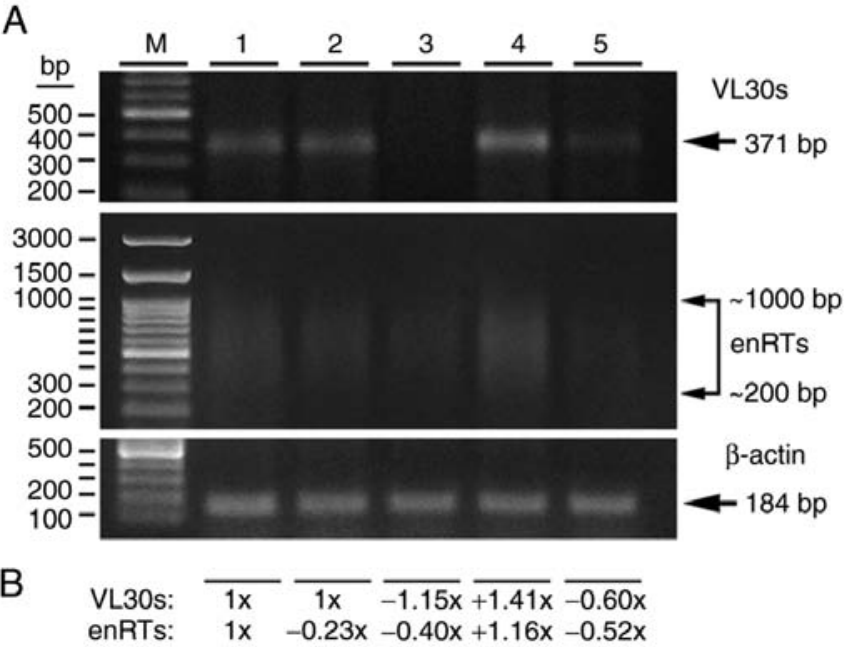

Figure 6. Tinzaparin inhibits the RNA expression of VL30 and enRT genes in $\mathrm{HC} 11$ cl.19 cells. (A) Low-confluence HC11 cl.19 cells were either untreated (lane 1) or treated with $2 \mathrm{IU} / \mathrm{ml}$ tinzaparin for 2 (lane 2) or $4 \mathrm{~h}$ (lane 3); treated with $12 \mathrm{ng} / \mathrm{ml}$ VEGF alone for $24 \mathrm{~h}$ (lane 4 ); or pre-incubated with $2 \mathrm{IU} / \mathrm{ml}$ tinzaparin for $4 \mathrm{~h}$ and then treated with $12 \mathrm{ng} / \mathrm{ml}$ VEGF (lane 5). RNA expression was assessed by semi-quantitative reverse transcription-PCR analysis using either specific VL30 or degenerated enRTs primers. (B) Fold-modulation (-x or $+\mathrm{x}$ ) of VL30 or enRT RNA expression is the $\beta$-actin-normalized net mean value subtracted from the respective RNA expression value of non-treated HC11 cl.19 cells (control) (1x, lane 1). Each numerical fold-modulation value is the mean of three measurements performed by densitometric analysis from three separate experiments. enRT, endogenous reverse transcriptase.

was further increased by VEGF treatment in a dose-dependent manner (Fig. 1A). A second line of evidence, clarifying and confirming the effect of VEGF on induction of VL30 retrotransposition, was obtained with NIH3T3 Pcl.10 cells (without pre-existing retrotransposition), where inducible VL30 retrotransposition is achieved solely after an external stimulus (35-37). In particular, while serum-starvation of Pcl.10 cells elicited $2.4 \%$ retrotransposition, this was further increased to $7.44 \%$ with $12 \mathrm{ng} / \mathrm{ml} \mathrm{VEGF,} \mathrm{attributed} \mathrm{to} \mathrm{both}$ serum-starvation and VEGF (Fig. S4). A third finding was that VEGF treatment of non-serum starved $\mathrm{HC} 11$ cl.19 cells significantly augmented VL30 and enRT RNA expression (Fig. 6, lane 4), required for the retrotransposition event. Thus, we hypothesize that VEGF is an effective inducer of VL30 retrotransposition in both breast epithelial stem-like cells and mouse fibroblasts, and that its action is intensified by serum starvation. Of note, VEGF is expressed in a wide variety of tumors, including human breast carcinoma (56), and transformed serum-starved v-H-ras or v-raf NIH3T3 cell lines express increased levels of VEGF mRNA and protein, compared with untransformed cells (57). These data imply that endogenous VEGF expression in $\mathrm{HC} 11$ cl.17 cells, similar to tumorigenic $\mathrm{HC} 11$ cl.19 cells (39), is involved either in their nominal, serum starvation- and exogenous VEGF-induced retrotransposition. By contrast, only serum starvation may be linked with endogenous VEGF expression- and serum starvation/VEGF-induced retrotransposition in NIH3T3 Pcl.10 cells (Fig. S4). To the best of our knowledge, the present study was the first such investigation in $\mathrm{HC} 11$ retrotransposition-positive cells and serum-starved NIH3T3 cells, thus the respective 
level of endogenous VEGF expression remains for detailed future investigation.

Regarding oxidative stress, concentration-dependent $\mathrm{GO} / \mathrm{H}_{2} \mathrm{O}_{2}$-induced retrotransposition was observed in HC11 cl.17 cells, compared with the nominal retrotransposition value (Fig. 2A). This supports a previous study showing strong $\mathrm{H}_{2} \mathrm{O}_{2}$-induced VL30 retrotransposition in Pcl.10 fibroblasts (44). Furthermore, considering $\mathrm{HC} 11$ cl.17 cells as tumorigenic (as the respective $\mathrm{HC} 11$ cl.19 cells) (39), and that tumor cells produce ROS (46), this explains the nominal retrotransposition of $\mathrm{HC} 11 \mathrm{cl} .17$ cells. Accordingly, the strong $\mathrm{GO} / \mathrm{H}_{2} \mathrm{O}_{2}$-induced retrotransposition was apparently due to the action of exogenously added $\mathrm{H}_{2} \mathrm{O}_{2}$, resulting in an increase in intracellular ROS in $\mathrm{HC} 11$ cl.17 cells. In agreement with these findings, the present study revealed that the sum of serum starvation and $12 \mathrm{ng} / \mathrm{ml} \mathrm{VEGF-induced} \mathrm{retrotransposition}$ in HC11 cl.17 (Fig. 1A) and Pcl.10 cells (Fig. S4) was higher than their respective serum starvation-treatment alone. It is known that serum-starved cells produce ROS, particularly $\mathrm{H}_{2} \mathrm{O}_{2}(54,58)$, therefore this may underline the contribution of serum starvation to the VEGF-induced retrotransposition of $\mathrm{HC} 11 \mathrm{cl} .17$ and Pcl.10 cells. Finally, in reference to the action of VEGF and intracellular $\mathrm{H}_{2} \mathrm{O}_{2}$, VEGF-treated HC11 cl.19 cells exhibited an induced VL30 and enRT RNA expression (Fig. 6, lane 4) 1.41- and 1.16-fold, respectively, exceeding those by intracellular-produced ROS (Fig. 6, lane 1). Thus, this justifies a higher VEGF-induced retrotransposition frequency compared with that induced by serum-starvation alone in HC11 cl.17 and Pcl.10 cells (Figs. 1A and S3), respectively. In addition, it is worth noting that oxidative stress and VEGF are linked, as intracellular oxidants and extracellular $\mathrm{H}_{2} \mathrm{O}_{2}$ correlate with the concomitant upregulation of VEGF transcription (59), that highlights oxidative stress as a primary stimulus of VL30 retrotransposition. Hence, we hypothesize that $\mathrm{H}_{2} \mathrm{O}_{2}$ per se is a strong inducer of VL30 retrotransposition in epithelial stem-like HC11 cells, and consequently, the augmented retrotransposition under serum starvation is explained by the cooperation of intracellular $\mathrm{H}_{2} \mathrm{O}_{2}$ with VEGF activity.

Serum-starved HC11 cl.17 cells pre-incubated with tinzaparin exhibited significantly reduced retrotransposition at all concentrations of VEGF tested. This was most evident with $12 \mathrm{ng} / \mathrm{ml}$ VEGF (inducing 40.3\% retrotransposition), which was reduced to $18.3 \%$ by tinzaparin (Fig. 1A). Furthermore, the tinzaparin effect was also time dependent (Fig. 1B). Apparently, the similar 18.3 - and $18.7 \%$ lowest values, even lower than the $29 \%$ serum starvation-induced retrotransposition scored in two independent experiments (Fig. 1A and B), corresponding to a $\sim 53 \%$ mean reduction value, document the strength of the tinzaparin effect. In addition, two more lines of evidence support this tinzaparin effect. First, tinzaparin pre-incubation of serum starved $12 \mathrm{ng} / \mathrm{ml}$ VEGF treated Pcl.10 cells reduced their retrotransposition in a time-dependent manner (Fig. S4). Second, a 3 h tinzaparin (1 or 2 IU) pre-incubation of $\mathrm{HC} 11 \mathrm{cl} .17$ cells reduced their expected (unusually high) GO-induced retrotransposition (Fig. 2B). Overall, given that: i) Tinzaparin pre-incubation strongly reduces VEGF- and/or oxidative stress-induced VL30 retrotransposition in epithelial HC11 and NIH3T3 fibroblasts; ii) a single 2 IU/ml dose elicits a strong reduction of VEGF-induced retrotransposition; iii) its drastic effect emerges rapidly, at a 3- to $4 \mathrm{~h}$ time point; and iv) it acts in a dose- and time-dependent manner; the current data highlight tinzaparin as a strong inhibitor of VL30 retrotransposition.

Based on the mechanism of LTR-retrotransposition, requiring both a homologous retrotransposon-intermediate transcript and RT activity (31), the action of tinzaparin was addressed at the transcription level. In particular, the RNA expression of both VL30s and enRTs in untreated HC11 cl.19 cells (Fig. 6, lane 1) primarily explains their nominal retrotransposition (due to intracellular-oxidative stress), given that these cells are tumorigenic (46) and produce ROS (60). Notably, the inhibitory effect of tinzaparin was documented: i) A direct tinzaparin treatment with $2 \mathrm{IU} / \mathrm{ml}$ for $4 \mathrm{~h}$ inhibited the RNA expression of VL30 elements and enRT below control levels (Fig. 6, lane 3); ii) their respective induced RNA expression with VEGF alone (Fig. 6, lane 4) was also inhibited upon pre-incubation with tinzaparin (Fig. 6, lane 5). Interestingly; and iii) $2 \mathrm{~h}$ tinzaparin pre-incubation inhibited only the RNA expression of enRTs (Fig. 6, lane 2), which mirrors its rapid effect on transcribed enRTs compared with VL30s. These data are in line with oxidative stress- and/or VEGF-induced retrotransposition inhibited by tinzaparin treatment. Furthermore, direct tinzaparin application: inhibited: i) The intracellular ROS-dependent VL30 and enRT RNA expression (Fig. 6, lane 3), and retrotransposition of disaggregated HC11 cl.19 cell mammospheres (Fig. 5C); ii) the induced retrotransposition (Figs. 1A and S4), attributed to the sum of intracellular- and serum starvation-ROS (54); and iii) strong retrotransposition induction by extracellular $\mathrm{GO} / \mathrm{H}_{2} \mathrm{O}_{2}$ (Fig. 2B). In reference to tinzaparin pre-incubation, it also inhibited both the VEGF-induced RNA expression of VL30s and enRTs (Fig. 6, lane 5), and VEGF-induced retrotransposition of HC11 cl. 17 (Fig. 1) and Pcl.10 cells (Fig. S4). These findings support that tinzaparin is an efficient inhibitor of VL30 retrotransposition, independently induced by either oxidative stress or VEGF, acting at the transcriptional level through inhibition of enRT and VL30 RNA expression.

The precise molecular pathways associated with the modulation of VL30 retrotransposition by oxidative stress, VEGF and/or tinzaparin, are unknown. Our previous studies have shown that VL30 retrotransposition is induced either by vanadium-generated $\mathrm{H}_{2} \mathrm{O}_{2}$ (41), arsenic-generated $\mathrm{ROS} / \mathrm{H}_{2} \mathrm{O}_{2}$ (42) or $\mathrm{H}_{2} \mathrm{O}_{2}$ alone (44). Furthermore, $\mathrm{H}_{2} \mathrm{O}_{2}$-induced retrotransposition was reported to be inhibited (as in the present study) by the anti-oxidant NAC $(42,44)$, or by the non-toxic/non-nucleoside specific reverse transcriptase inhibitors efavirenz or etravirine (44). As tinzaparin inhibited the RNA expression of VL30 and enRT genes, we hypothesize that tinzaparin acts similarly, both as an anti-oxidant and anti-retroviral drug.

Recombinant NVL-3/9 VL30 retrotransposon bears two activator protein-1 (AP-1) and an NF-kB transcription factor binding motifs at the $\mathrm{U} 3$ region of its LTR (38). An intermediate amount of ROS activates both NF-kB and AP-1 transcription factors (61), while VEGF also induces the expression of AP-1 family proteins (62). Therefore, NF-kB and AP-1 pathways may support the serum starvation- and/or VEGF or ROS/ $\mathrm{H}_{2} \mathrm{O}_{2}$-induced VL30 RNA expression required for the occurrence of a retrotransposition event. Regarding an active 
reverse transcriptase, an endogenous VL30-specific reverse transcriptase is yet to be identified, since as noncoding RNAs, VL30s are non-autonomous retrotransposons $(36,38)$. Our previous studies have shown that ectopic expression of a MoMLV-reverse transcriptase gene (40), acting in trans-complementation, induces VL30 retrotransposition that is further augmented by $\mathrm{H}_{2} \mathrm{O}_{2}(41)$. Given that MoMLV primers were included in the degenerate primers-set in the present study (to detect enRT RNA expression), this suggests that respective endogenous MoMLV-RT expression may be implicated in induced retrotransposition. While there are no data on induced MoMLV-RT enzyme activity (to the best of our knowledge), a possible mechanism may be similar to that of telomerase, activated by phosphorylation through the protein phosphatase 2-subunit $\mathrm{A}$, that is implicated in its negative regulation (63). It is, thus, reasonable to speculate that MoMLV activity was activated through the phosphatases known inhibition of $\mathrm{H}_{2} \mathrm{O}_{2}$ (64). Accordingly, this may endorse the inhibitory effect of tinzaparin on oxidative stress-induced VL30 retrotransposition preventing MoMLV-RT enzyme activation.

The present data support the inhibitory effect of tinzaparin on the proliferation of retrotransposition-positive HC11 cells, since tinzaparin-cultured $\mathrm{HC} 11 \mathrm{cl} .19$ or cl.15 cells showed time-dependent proliferation inhibition (Fig. 3A) up to $\sim 55$ and $\sim 60 \%$, respectively, at 5 days of culture (Fig. 3Ba and b). In addition, the effect of tinzaparin on cell foci and mammosphere formation was also shown. As HC11 cl.19 cells are tumorigenic CSCs (46), and as CSCs are referred to as tumor-initiating cells (29), the formation of cell foci either in semi-solid media (Fig. 4) or mammospheres in non-adherent surface dishes (Fig. 5Ab) was expected. Regarding cell foci formation, tinzaparin treatment led to cellular disaggregation with a reduced size of 3-6 cells (Fig. 4). This effect was more evident in preformed mammospheres, as their treatment produced single mesenchymal-like cells (Fig. 5Bc and d) accompanied by a significant inhibition of retrotransposition (Fig. 5C). This shows an association between tinzaparin-inhibited retrotransposition and mammosphere disaggregation, without affecting the EMT-induced phenotype (46) of $\mathrm{HC11}$ cl.19 cells. It is thought that a low intracellular level of ROS is tightly controlled to promote proliferation and survival of stem and progenitor cells (65), while enRTs, active in germ cells, embryo and tumor tissues, are considered mediators of cellular differentiation and proliferation (66). These findings may explain the inhibited proliferation and associated retrotransposition caused by the anti-oxidant and/or anti-retroviral effects of tinzaparin.

The exact molecular mechanisms underlying the dual action of tinzaparin on mammosphere-disaggregation, and proliferative inhibition of disaggregated cells, is yet to be elucidated. It appears that the cell surface heparan sulfate proteoglycans (HSPGs) are implicated in the mammosphere formation of $\mathrm{HC} 11 \mathrm{cl} .19$ cells (Fig. 5Ab), as they most commonly bind to secondary sites on cell adhesion molecules, and increase the strength of intercellular adhesions and cell-cell stability (67). However, heparin potentially inhibits cell-cell interactions by binding to cellular adhesion molecules (68). Hence, we hypothesize that tinzaparin interferes with the intercellular adhesion process, resulting in mammosphere disaggregation (Fig. 5Bc and d), and reduces foci size (Fig. 4). In addition, the proliferation of disaggregated cells can be inhibited either by soluble HSPGs, as shown in pancreatic cancer cells (69), or by soluble HSPGs or heparin, shown in neuroblastoma cells (70). Accordingly, the present study supports that, in addition to its anti-oxidant/anti-retroviral effects, tinzaparin (as a low molecular weight heparin) stimulates the production of soluble HSPGs, which in turn inhibit the proliferation of disaggregated tumorigenic HC11 cl.19 cells, a matter that warrants further investigation.

It is noteworthy that the natural retrotransposition frequency for a defective retrotransposon, such as VL30, is estimated to be up to $10^{-6}$ events per cell/generation (33). By contrast, unusually high retrotransposition frequencies were noted in the present study. For example; $40 \%$ by serum-starvation/VEGF treatment (Fig. 1A), corresponding to a 400,000-fold induced retrotransposition. Apparently, such accumulation of new genomic integrated retrotransposon copies can cause numerous mutations, underlining the detrimental effects of VL30 retrotransposition. Therefore, the present data, showing that tinzaparin inhibits retrotransposition, underlines the prophylactic property of tinzaparin against accumulated VL30 retrotransposition mutations. Finally, human breast cancer mammosphere-forming cells display resistance to chemotherapeutic drugs $(71,72)$. In this sense, our mouse HC11-VL30 retrotransposition model could be used as a preliminary in vitro assay to evaluate the efficacy of novel chemotherapeutic drugs.

To the best of our knowledge, the present study associates, for the first time, the action of tinzaparin with the inhibition of VL30 retrotransposition, being a causative factor of tumorigenesis in HC11 mammary epithelial stem-like cells. The data, extending the properties of tinzaparin as an anticoagulant agent and angiogenesis inhibitor, reveal three additional tinzaparin-interconnected actions: i) Tinzaparin acts as an anti-oxidant and anti-retroviral drug against VL30 retrotransposition induced by oxidative-stress and/or VEGF, providing prophylaxis against new VL30 retrotransposition-derived genomic mutations; ii) tinzaparin exerts anti-proliferative action on CSCs; and iii) tinzaparin is effective in disaggregating mammosphere-formation to intercept tumor growth. As tinzaparin activity is associated with transcriptional reprogramming of a plethora of genes (17), the VL30 retrotransposition model may potentially be used in elucidating its impact on diverse biological processes in $\mathrm{HC} 11$ cells.

\section{Acknowledgements}

Not applicable.

\section{Funding}

The present study was financially supported by two funds (grant no. 80899 and 81423) from the LEO Pharmaceuticals (Athens, Greece).

\section{Availability of data and materials}

The datasets used and/or analyzed during the current study are available from the corresponding author on reasonable request.

\section{Authors' contributions}

SM performed the laboratory experiments. GM directed the study, evaluated the flow cytometric data and prepared the 
original manuscript. GV and DN performed the flow cytometric analysis. ST and FG assisted with the cell culture experiments. TT conceived, designed and supervised the experiments, and wrote the manuscript. SM and TT confirm the authenticity of all the raw data. All authors read and approved the final manuscript.

\section{Ethics approval and consent to participate}

Not applicable.

\section{Patient consent for publication}

Not applicable.

\section{Competing interests}

The authors declare that they have no competing interests, or any other personal connections with, or are employed by, LEO Pharmaceuticals.

\section{References}

1. Khorana AA and Connolly GC: Assessing risk of venous thromboembolism in the patient with cancer. J Clin Oncol 27 4839-4847, 2009.

2. Mandalà M, Falanga A and Roila F; ESMO Guidelines Working Group: Management of venous thromboembolism (VTE) in cancer patients: ESMO clinical practice guidelines. Ann Oncol 22 (Supp 6): vi85-vi92, 2011.

3. Lyman GH, Bohlke K, Khorana AA, Kuderer NM, Lee AY, Arcelus JI, Balaban EP, Clarke JM, Flowers CR, Francis CW, et al: Venous thromboembolism prophylaxis and treatment in patients with cancer: American society of clinical oncology clinical practice guideline update 2014. J Clin Oncol 33: 654-656, 2015.

4. Dahlbäck B: Blood coagulation. Lancet 355: 1627-1632, 2000.

5. Wong NN: Tinzaparin. Heart Dis 4: 331-340, 2002.

6. Horton J: Venous thrombotic events in cancer: The bottom line. Cancer Control 12 (Suppl 1): S31-S37, 2005.

7. Scotté F, Rey JB and Launay-Vacher V: Thrombosis, cancer and renal insufficiency: Low molecular weight heparin at the crossroads. Support Care Cancer 20: 3033-3042, 2012.

8. Perry SL, Bohlin C, Reardon DA, Desjardins A, Friedman AH, Friedman HS and Vredenburgh JJ: Tinzaparin prophylaxis against venous thromboembolic complications in brain tumor patients. J Neurooncol 95: 129-134, 2009.

9. Stevenson JL, Choi SH and Varki A: Differential metastasis inhibition by clinically relevant levels of heparins-correlation with selectin inhibition, not antithrombotic activity. Clin Cancer Res 11: 7003-7011, 2005.

10. Schlesinger M, Roblek M, Ortmann K, Naggi A, Torri G, Borsig L and Bendas G: The role of VLA-4 binding for experimental melanoma metastasis and its inhibition by heparin. Thromb Res 133: 855-862, 2014

11. Harvey JR, Mellor P, Eldaly H, Lennard TW, Kirby JA and Ali S: Inhibition of CXCR4-mediated breast cancer metastasis: A potential role for heparinoids? Clin Cancer Res 13: 1562-1570, 2007.

12. Alyahya R, Sudha T, Racz M, Stain SC and Mousa SA Anti-metastasis efficacy and safety of non-anticoagulant heparin derivative versus low molecular weight heparin in surgical pancreatic cancer models. Int J Oncol 46: 1225-1231, 2015.

13. Bauer AT, Suckau J, Frank K, Desch A, Goertz L, Wagner AH, Hecker M, Goerge T, Umansky L, Beckhove P, et al: von Willebrand factor fibers promote cancer-associated platelet aggregation in malignant melanoma of mice and humans. Blood 125: 3153-3163, 2015.

14. Amirkhosravi A, Mousa SA, Amaya M and Francis JL: Antimetastatic effect of tinzaparin, a low-molecular-weight heparin. J Thromb Haemost 1: 1972-1976, 2003.

15. Mousa SA and Mohamed S: Anti-angiogenic mechanisms and efficacy of the low molecular weight heparin, tinzaparin: Anti-cancer efficacy. Oncol Rep 12: 683-688, 2004.
16. Mousa SA and Mohamed S: Inhibition of endothelial cell tube formation by the low molecular weight heparin, tinzaparin, is mediated by tissue factor pathway inhibitor. Thromb Haemost 92: 627-633, 2004

17. Pfankuchen DB, Stölting DP, Schlesinger M, Royer HD and Bendas G: Low molecular weight heparin tinzaparin antagonizes cisplatin resistance of ovarian cancer cells. Biochem Pharmacol 97: 147-157, 2015.

18. Dimakakos EP, Vathiotis I and Syrigos K: The role of tinzaparin in oncology. Clin Appl Thromb Hemost 24: 697-707, 2018.

19. Kragh M, Binderup L, Vig Hjarnaa PJ, Bramm E, Johansen KB and Frimundt Petersen C: Non-anti-coagulant heparin inhibits metastasis but not primary tumor growth. Oncol Rep 14: 99-104, 2005.

20. Folkman J: Angiogenesis in cancer, vascular, rheumatoid and other disease. Nat Med 1: 27-31, 1995.

21. Carmeliet P and Jain RK: Angiogenesis in cancer and other diseases. Nature 407: 249-257, 2000

22. Gamperl H, Plattfaut C, Freund A, Quecke T, Theophil F and Gieseler F: Extracellular vesicles from malignant effusions induce tumor cell migration: Inhibitory effect of LMWH tinzaparin. Cell Biol Int 40: 1050-1061, 2016.

23. Sudha T, Yalcin M, Lin HY, Elmetwally AM, Nazeer T, Arumugam T, Phillips P and Mousa SA: Suppression of pancreatic cancer by sulfated non-anticoagulant low molecular weight heparin. Cancer Lett 350: 25-33, 2014

24. Guarino M, Rubino B and Ballabio G: The role of epithelial-mesenchymal transition in cancer pathology. Pathology 39: 305-318, 2007.

25. Hugo H, Ackland ML, Blick T, Lawrence MG, Clements JA, Williams ED and Thompson EW: Epithelial-mesenchymal and mesenchymal-epithelial transitions in carcinoma progression. J Cell Physiol 213: 374-383, 2007.

26. Yang AD, Camp ER, Fan F, Shen L, Gray MJ, Liu W, Somcio R, Bauer TW, Wu Y, Hicklin DJ and Ellis LM: Vascular endothelial growth factor receptor-1 activation mediates epithelial to mesenchymal transition in human pancreatic carcinoma cells. Cancer Res 66: 46-51, 2006.

27. Hayashida T, Jinno H, Kitagawa Y and Kitajima M: Cooperation of cancer stem cell properties and epithelial-mesenchymal transition in the establishment of breast cancer metastasis. J Oncol 2011: 591427, 2011.

28. Mani SA, Guo W, Liao MJ, Eaton EN, Ayyanan A, Zhou AY, Brooks M, Reinhard F, Zhang CC, Shipitsin M, et al: The epithelial-mesenchymal transition generates cells with properties of stem cells. Cell 133: 704-715, 2008.

29. Al-Hajj M, Wicha MS, Benito-Hernandez A, Morrison SJ and Clarke MF: Prospective identification of tumorigenic breast cancer cells. Proc Natl Acad Sci USA 100: 3983-3988, 2003.

30. Cordaux R and Batzer MA: The impact of retrotransposons on human genome evolution. Nat Rev Genet 10: 691-703, 2009.

31. Boeke JD, Garfinkel DJ, Styles CA and Fink GR: Ty elements transpose through an RNA intermediate. Cell 40: 491-500, 1985.

32. Hancks DC and Kazazian HH Jr: Roles for retrotransposon insertions in human disease. Mob DNA 7: 9, 2016.

33. Heidmann T, Heidmann O and Nicolas JF: An indicator gene to demonstrate intracellular transposition of defective retroviruses. Proc Natl Acad Sci USA 85: 2219-2223, 1988.

34. Georgiou I, Noutsopoulos D, Dimitriadou E, Markopoulos G, Apergi A, Lazaros L, Vaxevanoglou T, Pantos K, Syrrou M and Tzavaras T: Retrotransposon RNA expression and evidence for retrotransposition events in human oocytes. Hum Mol Genet 18: 1221-1228, 2009.

35. Goodier JL and Kazazian HH Jr: Retrotransposons revisited: The restraint and rehabilitation of parasites. Cell 135: 23-35, 2008.

36. French NS and Norton JD: Structure and functional properties of mouse VL30 retrotransposons. Biochim Biophys Acta 1352: 33-47, 1997.

37. Garen A and Song X: Regulatory roles of tumor-suppressor proteins and noncoding RNA in cancer and normal cell functions. Int J Cancer 122: 1687-1689, 2008.

38. Markopoulos G, Noutsopoulos D, Mantziou S, Gerogiannis D, Thrasyvoulou S, Vartholomatos G, Kolettas E and Tzavaras T: Genomic analysis of mouse VL30 retrotransposons. Mob DNA 7: 10, 2016.

39. Brunmeir R, Lagger S, Simboeck E, Sawicka A, Egger G, Hagelkruys A, Zhang Y, Matthias P, Miller WJ and Seiser C: Epigenetic regulation of a murine retrotransposon by a dual histone modification mark. PLoS Genet 6: e1000927, 2010. 
40. Noutsopoulos D, Vartholomatos G, Kolaitis N and Tzavaras T: SV40 large $\mathrm{T}$ antigen up-regulates the retrotransposition frequency of viral-like 30 elements. J Mol Biol 361: 450-461, 2006.

41. Noutsopoulos D, Markopoulos G, Koliou M, Dova L, Vartholomatos G, Kolettas E and Tzavaras T: Vanadium induces VL30 retrotransposition at an unusually high level: A possible carcinogenesis mechanism. J Mol Biol 374: 80-90, 2007.

42. Markopoulos G, Noutsopoulos D, Mantziou S, Vartholomatos G, Monokrousos N, Angelidis C and Tzavaras T: Arsenic induces VL30 retrotransposition: The involvement of oxidative stress and heat-shock protein 70. Toxicol Sci 134: 312-322, 2013.

43. Tzavaras T, Eftaxia S, Tavoulari S, Hatzi P and Angelidis C: Factors influencing the expression of endogenous reverse transcriptases and viral-like 30 elements in mouse NIH3T3 cells. Int J Oncol 23: 1237-1243, 2003.

44. Konisti S, Mantziou S, Markopoulos G, Thrasyvoulou S, Vartholomatos G, Sainis I, Kolettas E, Noutsopoulos D and Tzavaras T: H2O2 signals via iron induction of VL30 retrotransposition correlated with cytotoxicity. Free Radic Biol Med 52: 2072-2081, 2012.

45. Noutsopoulos D, Markopoulos G, Vartholomatos G, Kolettas E, Kolaitis N and Tzavaras T: VL30 retrotransposition signals activation of a caspase-independent and p53-dependent death pathway associated with mitochondrial and lysosomal damage. Cell Res 20: 553-562, 2010.

46. Thrasyvoulou S, Vartholomatos G, Markopoulos G, Noutsopoulos D, Mantziou S, Gkartziou F, Papageorgis P, Charchanti A, Kouklis P, Constantinou AI and Tzavaras T: VL30 retrotransposition is associated with induced EMT, CSC generation and tumorigenesis in HC11 mouse mammary stem-ike epithelial cells. Oncol Rep 44: 126-138, 2020.

47. Ball RK, Friis RR, Schoenenberger CA, Doppler W and Groner B: Prolactin regulation of beta-casein gene expression and of a cytosolic $120-\mathrm{kd}$ protein in a cloned mouse mammary epithelial cell line. EMBO J 7: 2089-2095, 1988.

48. Williams C, Helguero L, Edvardsson K, Haldosén LA and Gustafsson JA: Gene expression in murine mammary epithelial stem cell-like cells shows similarities to human breast cancer gene expression. Breast Cancer Res 11: R26, 2009.

49. Borowicz S, Van Scoyk M, Avasarala S, Karuppusamy Rathinam MK, Tauler J, Bikkavilli RK and Winn RA: The soft agar colony formation assay. J Vis Exp: e51998, 2014.

50. Ostertag EM, Prak ET, DeBerardinis RJ, Moran JV and Kazazian HH Jr: Determination of L1 retrotransposition kinetics in cultured cells. Nucleic Acids Res 28: 1418-1423, 2000.

51. Xiong Y and Eickbush TH: Origin and evolution of retroelements based upon their reverse transcriptase sequences. EMBO J 9: 3353-3362, 1990.

52. Puschendorf M, Stein P, Oakeley EJ, Schultz RM, Peters AH and Svoboda P: Abundant transcripts from retrotransposons are unstable in fully grown mouse oocytes. Biochem Biophys Res Commun 347: 36-43, 2006.

53. Bloushtain-Qimron N, Yao J, Snyder EL, Shipitsin M, Campbell LL, Mani SA, Hu M, Chen H, Ustyansky V, Antosiewicz JE, et al: Cell type-specific DNA methylation patterns in the human breast. Proc Natl Acad Sci USA 105: 14076-14081, 2008.

54. White EZ, Pennant NM, Carter JR, Hawsawi O, Odero-Marah V and Hinton CV: Serum deprivation initiates adaptation and survival to oxidative stress in prostate cancer cells. Sci Rep 10: 12505, 2020

55. Merlo GR, Venesio T, Taverna D, Marte BM, Callahan R and Hynes NE: Growth suppression of normal mammary epithelial cells by wild-type p53. Oncogene 9: 443-453, 1994.
56. Ferrara $\mathrm{N}$ and Davis-Smyth $\mathrm{T}$ : The biology of vascular endothelial growth factor. Endocr Rev 18: 4-25, 1997.

57. Grugel S, Finkenzeller G, Weindel K, Barleon B and Marmé D: Both v-Ha-Ras and v-Raf stimulate expression of the vascular endothelial growth factor in NIH 3T3 cells. J Biol Chem 270: 25915-25919, 1995

58. Scherz-Shouval R, Shvets E, Fass E, Shorer H, Gil L and Elazar Z: Reactive oxygen species are essential for autophagy and specifically regulate the activity of Atg4. EMBO J 26: 1749-1760, 2007.

59. Wu Y, Meitzler JL, Antony S, Juhasz A, Lu J, Jiang G, Liu H, Hollingshead M, Haines DC, Butcher D, et al: Dual oxidase 2 and pancreatic adenocarcinoma: IFN- $\gamma$-mediated dual oxidase 2 overexpression results in $\mathrm{H} 2 \mathrm{O} 2$-induced, ERK-associated up-regulation of HIF- $1 \alpha$ and VEGF-A. Oncotarget 7: 68412-68433, 2016.

60. Szatrowski TP and Nathan CF: Production of large amounts of hydrogen peroxide by human tumor cells. Cancer Res 51: 794-798, 1991.

61. Gloire G, Legrand-Poels S and Piette J: NF-kappaB activation by reactive oxygen species: Fifteen years later. Biochem Pharmacol 72: 1493-1505, 2006.

62. Jia J, Ye T, Cui P, Hua Q, Zeng H and Zhao D: AP-1 transcription factor mediates VEGF-induced endothelial cell migration and proliferation. Microvasc Res 105: 103-108, 2016.

63. Liu JP: Studies of the molecular mechanisms in the regulation of telomerase activity. FASEB J 13: 2091-2104, 1999.

64. Reth M: Hydrogen peroxide as second messenger in lymphocyte activation. Nat Immunol 3: 1129-1134, 2002.

65. Kobayashi CI and Suda T: Regulation of reactive oxygen species in stem cells and cancer stem cells. J Cell Physiol 227: 421-430, 2012.

66. Spadafora C: Endogenous reverse transcriptase: A mediator of cell proliferation and differentiation. Cytogenet Genome Res 105: 346-350, 2004

67. Bernfield M, Götte M, Park PW, Reizes O, Fitzgerald ML, Lincecum J and Zako M: Functions of cell surface heparan sulfate proteoglycans. Annu Rev Biochem 68: 729-777, 1999.

68. Bendas G and Borsig L: Cancer cell adhesion and metastasis: Selectins, integrins, and the inhibitory potential of heparins. Int J Cell Biol 2012: 676731, 2012

69. Knelson EH, Nee JC and Blobe GC: Heparan sulfate signaling in cancer. Trends Biochem Sci 39: 277-288, 2014.

70. Knelson EH, Gaviglio AL, Nee JC, Starr MD, Nixon AB Marcus SG and Blobe GC: Stromal heparan sulfate differentiates neuroblasts to suppress neuroblastoma growth. J Clin Invest 124: 3016-3031, 2014.

71. Creighton CJ, Li X, Landis M, Dixon JM, Neumeister VM, Sjolund A, Rimm DL, Wong H, Rodriguez A, Herschkowitz JI, et al: Residual breast cancers after conventional therapy display mesenchymal as well as tumor-initiating features. Proc Natl Acad Sci USA 106: 13820-13825, 2009.

72. Ji P, Zhang Y, Wang SJ, Ge HL, Zhao GP, Xu YC and Wang Y: CD44hiCD24lo mammosphere-forming cells from primary breast cancer display resistance to multiple chemotherapeutic drugs. Oncol Rep 35: 3293-3302, 2016.

This work is licensed under a Creative Commons Attribution-NonCommercial-NoDerivatives 4.0 International (CC BY-NC-ND 4.0) License. 